Patients' right to know if their physician has the acquired immunodeficiency disease (AIDS) outweighs the physician's right to privacy, ruled a New Jersey Superior Court.

"The ultimate risk to the patient is so absolute, so devastating, that it is untenable to argue against informed consent, combined with a restriction on procedures which present any risk to the patient," said Superior Court Justice Philip S. Carchman in his decision.

"At a minimum, the physician must withdraw from performing any invasive procedure which would pose a risk to the patient."

This ruling is the first time patients' right to know was pitted against HIV-infected healthcare workers' right to privacy.

Plastic surgeon William Behringer, MD, filed a discrimination lawsuit against The Medical Center at Princeton, saying his suspension violated a New Jersey law that prohibits discrimination against AIDS-infected persons. The hospital had suspended Dr Behringer after he tested positive for the human immunodeficiency virus in 1987.

Dr Behringer died in 1989 and his estate continued the lawsuit.

In his decision, Justice Carchman upheld the hospital's right to suspend Dr Behrin- ger. However, he said that the hospital violated Dr Behringer's right to confidentiality when the institution failed to keep private the information about Dr Behringer's illness. Justice Carchman also noted that Dr Behringer lost approximately $\$ 600,000$ from his practice during the 2 years after the public disclosure of his illness.

"AIDS is such an emotional subject that right-to-know is given disproportionate significance," says Roger Bernstein, an attorney for Dr Berhinger's estate.

Damages were expected to be awarded at a later date, reports the April 26 issue of the Chicago Sun-Times.

University administrators across America need to fight drug and alcohol abuse more aggressively on campus, says Bob Martinez, the new director of the Office of National Drug Control Policy.

Citing a drug raid on the University of Virginia campus in March in which 12 students were arrested and more than 12 bags of marijuana and hallucinogenic mushrooms were seized, Martinez said, "I do believe there's a general weakness of university administrators to tackle the problem."
Because many colleges and universities receive federal aid, these institutions of higher learning should do more to support national drugcontrol policies, says Martinez. "That means more than simply posting bulletins at the back of the student union. It means a real aggressive program."

Administrators at the University of Virginia, as well as other universities, defended their drug control efforts, noting that most schools have adequate antidrug programs and that overall, drug use has declined among students.

Despite this overall decline, Martinez says he has "every reason to believe [drug use] will continue. I don't think we have reached an end [to what can be done]."

His comments appear in the April 19 issue of the $\mathrm{Chi}$ cago Tribune.

If the average 35-year-old American eliminates risk factors associated with heart disease from his or her lifestyle, such a person will increase longevity by a mere 3 years.

The slight gain in longevity can be explained by the other diseases and illnesses, including cancer and pneumonia, that claim the lives of Americans aged 80 and older.

(continued on page 531) 
Patients taking

antihistamines may have

impaired performance

without feeling drowsy ${ }^{1,2}$

\section{HUMAN PERFORMANCE}

\section{DEMANDSAN} ANTIHISTAMINE PROVEN TO

FREE PATIENTS FROM IMPAIRED PERFORMANCE ${ }^{2.23}$

Impairment-free relief

from the first dose through the season

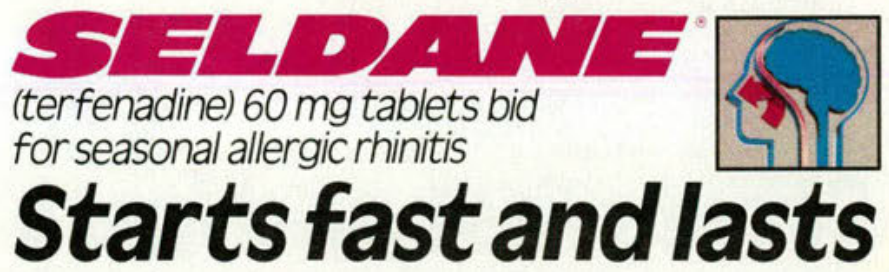




\section{COONTIVE PERFORMANCE}

\section{DEMANDSAN}

ANTIHISTAMINE

PROVEN

TOHAVE

NO EFFECTS ON

COGNITIVE

EFFICIENCY AND

ATTENTION SPAN

GREATER THAN

PLACEBO

Impairment-free relief

from the first dose through the season

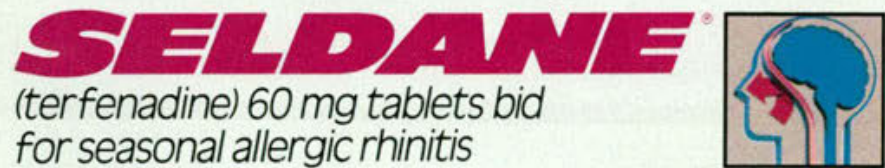

for seasonal allergic rhinitis

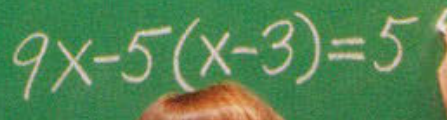

Starts fast and lasts 
MOTOR PERFORMANCE

DEMANDS AN ANTIHISTAMINE PROVEN TO HAVE NO EFFECTS ON REACTION TIME AND MOTOR COORDINATION GREATER THAN PLACEBO

Lack of performance impairment must be proven through extensive objective testing-distinct from subjectively reported drowsiness ${ }^{24.25}$ More than 60 objective tests of cognitive, motor, and integrated performancedocumented in over 20 published studies-show that Seldane has no effects on human performance greater than placebo ${ }^{2-22}$ 
SELDANE

FREES PATIENTS

FROM

PERFORMANCE

IMPAIRMENT

CAUSEDBY

CLASSICAL

ANTIHISTAMINES,

WHILE IT

PROVIDES FAST, STRONG RELIEF

- Effects on patient performance no greater than placebo

- Lets patients stay alert

- Strong through-theseason relief

- Convenient 24-hour relief at recommended dosage

- Proven worldwide with more than 100 million patient-months of use

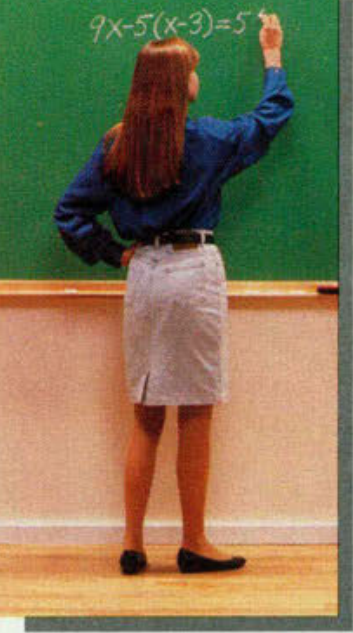

Seldane ${ }^{\odot}$

(tertenadine) $60 \mathrm{mg}$

w prohibits dispensing without prescription.

DESCRIPTION

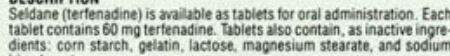

INDICATIONS AND USAGE

Seldane is indicated for the relief of symptoms associated with seasona allergic rhinitis such as

Seldane is contraindicuted in gatients with a known hypersensitivity to

tertenadine or any of its ingredients.

PRECAUTIONS

(a) Patients

with impaired hepatic function (aicoholic cirrhosis, hepatitis), or of

prolongation (eg- hypokalemia, congental ot syndrome) may expentence

The effect of terfenadine in patients who are receiving agents which alter

the or interval is not known. These events have also occurred in patients

On macrolide antibiotics, including erythrom
The events man, but causality is uncleat

Intormation for patients: Patients taking Seldane should receive the follow ing information and instructions. Antihistamines are prescribed to reduce allergic symptoms. Patients should be questijned about pregnancy of pregnancy or lactation only if the potential benefiti iustifies the potential ris to fetus or baby. Patients should be instructed to take Seldane only as neede and
to store this medication in a tightly closed container in a cool, dry place. Drug interactions: Preliminary evidence exists that concurrent ketocona.
zole or mactolide administration significantily alters the metabolism of

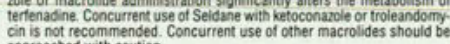

Carcinogenesis, mutagenesis, impairment of fertility - Oral doses of terin mice for 18 months or in rats for 24 months, revealed no evidence tumorigenicity Microbial and micronucleus test assags with terfenadine have

Peproduction and fertility studies in rats showed no effects on male or female the hum an 125 fimes and ar 2 times the human dayy dose reduced imolants and increased post. mal toxicty

Pregnancy Categary $C$ : There was no evidence of animal teratogenicity 125 times the human dzily dose and have revealed decreased pup weig gain and survivic when terienadine was administered throughour pregnang and lactation. There are no adequate and well-controlled studies in
pregnant women. Seldane should be used during pregnancy only if the
potential benefit ustifies the potential risk to the tetus.

Nonteratogenic effects: Seldane is not recommended for nursing women. doses 63 times and 125 times the human dal y dose throughout preganan and lactation. Effects on pups exposed to Seldane onty during lactation are

Pedatric use: Salety and effectiveness of Seldane in children below the age of 12 years have not been establishes.

ADVERSE REACTIONS

Experiencefrumcinical studies, including both controlled and uncontrolled information on adverse experience incidence for periods of a few days un to six months. The usual dose in these stucies was 60 mg twice daily. but in a small number of patients,
of as high as $600 \mathrm{mg}$ daily.
In controlled clinical studies using the recommended dose of $60 \mathrm{mg}$ bio. similar to that reported in patients receiving placebo (See table below) ADVEASE EVENTS REPORTED IN CLINICAL TRIALS

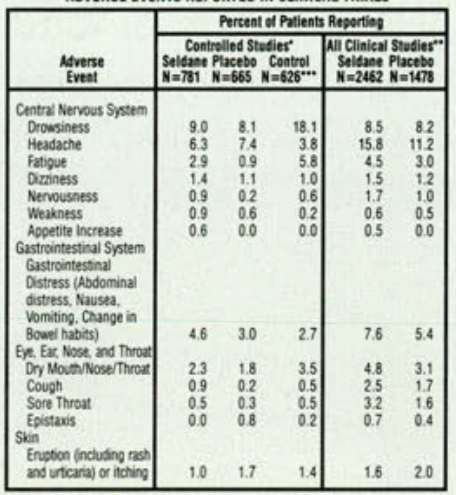

Ouration of treatment in "CONTROLLED STUDIES" was usually 7 7-14 "Duration of treatmentin "ALL CUNCAL STUDIES" was up to 6 months CONTROLL DAUGS: Chlorpheniramine (291 pattints
mine (189 patients). Clemastine (146 patients)

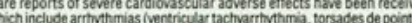
ventricular tion lation), hypotension, palotations, and syncope in control

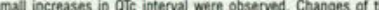

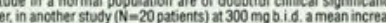
afc of $109 \%$ (range $-4 \%$ to $+30 \% 6$ ) (mean increase of $46 \mathrm{msec}$ ) was

reported in clinical triass (See Frials and or spontanesussyly during marketing of Selidane that warrant lis. actosketet. photosensitivity, seizures, sinus tachycardia. sweating, tremor, urinary in clinical trials, several instances of mild, or in one case, moderate trans. solated reports of aundice. cholestatciepaltis, and hepatitis. In most cases OVERDOSAGE

Information concerning poss

DOSAGE AND ADMINISTRATION Product information as of July, 1990

Prescription Products Division
Kansas City, M0 64114 .
Impairment-free relief

from the first dose through the season

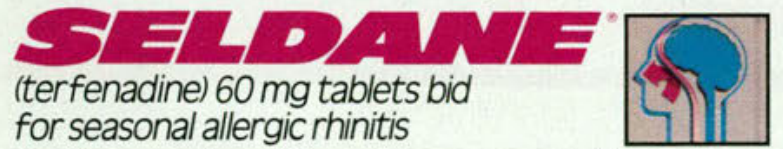

Starts fast and lasts
References: 1. Seidel WF, Cohen S, Bliwise NG, et al. Ann Allergy, 1987:59010-58-62 2. Clarke CH. Nicho AN. Br J Clin Pharmacol 1978,6:31-35. 3. Swire FMM, Marsden CA, Barber C, et al. Psychopharmacology 1989,98425-429. 4. Nicholson AN, Stone BM. Eur J Clin Pharmacol 1983;25:563-566. 5. Nicholson AN, S BM. Br J Clin Pharmacol 1982,13:199-202 6. Nicholson AN, Smith PA. Spencer MB Br J Clin Pharmacol 192,14.683-690.7. Reinberg A, Levi F, Guillet P, et al. Eur J Clin Pharmacol. 1978,14:245-252. 8. Moser JE, et al. J Allergy Clin immunol 1989,84:316-322. 10. Weiner M. Arzneim-Forsch/Drug Res 1982:32 110.1 1195. 11. Meador KJ, Loring DW, Thompson EE, et al. J Allergy Clin Immunol. 1989:84:322-325. 12. Aso Sakai Y. Jpn J Clin Pharmacol Ther. 1988,19(4).681-688. 13. Luscombe DK. Nicholls PJ, Parish PA. Pharmati peutica 1983:3:370-375. 14. Gaillard AWK, Gruisen A de Jong R. Eur J Clin Pharmacol. 1988:35:249-25 15. Moskowitz H, Burns M. Cutis 1988:42:1418. 16. Cohen AF, Hamilton MJ, Peck AW. Eur J Clin Pharma 1987:32:279-288. 17, Roehrs TA, Tietz El, Zorick FJ, et al. Sleep 1984,7(2):137-141. 18. Fink M, Irwin P. Phar 20. 1978.6-25-29. 22. Nicholson AN Stone BM Eur J Clin Pharmacol 1986:30.27-32 23. Data on file Mario Merrell Dow inc. Kansas City, MO 64114. 24. Broadbent DE. Br J Clin Pharmacol. 1984,18:5S.9S. 25. Hindmarch L. Br J Clin Pharmacol. 1980,10,189-209. 
"If you wipe out heart disease, people don't live forever," said Lee Goldman, MD, of Brigham and Women's Hospital in Boston, coauthor of the study on which these findings are based. "Heart disease is the leading killer, but there are other things people die from."

Dr Goldman developed a computer program that predicts longevity based on answers to a series of health-related questions, such as, "What if all Americans reduced their cholesterol levels below $200 \mathrm{mg} / \mathrm{dL}$ ?" and "What if everyone stopped smoking?" Dr Goldman's colleagues include researcher Milton Weinstein of Harvard School of Public Health, and principal author and researcher Joel Tsvat of Beth Israel Hospital in Boston.

Specifically, the study found that the average 35-year-old man who reduces his cholesterol level below $200 \mathrm{mg} / \mathrm{dL}$ will add 8 months to his life. Stopping smoking will add 10 months, while dropping those extra pounds will add another 7 months to life, and controlling high blood pressure adds a full year. Women who make such changes would add another 10 months, 8 months, 5 months, and 5 months, respectively to their longevity. In particular, persons with any of these health risks who make such changes would gain the most in extra lifetime, accord- ing to computer projections.

Complete study results are published in the April issue of Circulation.

\section{Serum prostate-specific an-} tigen (PSA) levels can be used effectively to screen for prostate cancer, according to a study appearing in the April 25 issue of The New England Journal of Medicine.

Using a PSA measurement of $\geq 4 \mu \mathrm{g} / \mathrm{L}$ as an index of suspicion for prostate cancer, researchers detected cancer in 85 of 107 men $(22 \%)$. (This serum PSA concentration determined whether study participants underwent rectal examinations and prostatic ultrasonography.)Biopsies were performed on men with abnormal findings on rectal examination, ultrasonography, or both.

Among those 30 men with a PSA level $\geqslant 10 \mu \mathrm{g} / \mathrm{L}, 27$ men underwent biopsies; cancer was detected in 18 of them $(67 \%)$. Serum PSA measurements had an overall accuracy rate of $64 \%$. When combined with rectal examination and ultrasonography, PSA serum concentration provides a better method of detecting prostate cancer than rectal examination alone, conclude the researchers.

"It's very conceivable that using this test, the statistics in prostate cancer could be dramatically altered," says William J. Catalona, MD, one of the authors of this study. "Instead of seven out of 10 cases of cancer being advanced at the time of diagnosis, we could flip-flop that, and seven out of 10 could be early-stage cancer."

But not everyone in the medical community shares Dr Catalona's enthusiasm for this screening approach. "PSA is a useful tool for following patients with known prostate cancer, but it is still not a useful tool for screening. It's not sensitive or specific enough," comments Michael P. O'Leary, MD, of New England Medical Center in Boston.

In the current study reported, serum PSA concentrations had a specificity of $59 \%$ and sensitivity of $79 \%$. Rectal examination had a specificity of $44 \%$ and sensitivity of $86 \%$, while ultrasonography had a specificity of $27 \%$ and a sensitivity of $92 \%$.

\footnotetext{
Baby-boomers are having babies in near-record numbers, according to the April report from the National Center for Health Statistics.

The nationwide birthrate for 1990 was 16.7 per 1000 women, the highest rate since 1971. The number of women between 30 and 34 years of (continued on page 534)
} 


\section{Fast, powerful relief for pain/inflammation}

Sprains \& Strains 


\section{Helps trauma patients get back to work faster.}

No oral analgesic works faster-onset of pain relief may occur as fast as 20 minutes Pain relief as powerful as the codeine combinations and propoxyphene napsylate ${ }^{2}$ Potent anti-inflammatory effect helps promote return to full function by reducing swelling and inflammation'

\section{Fast Relief. Fast Recovery.}

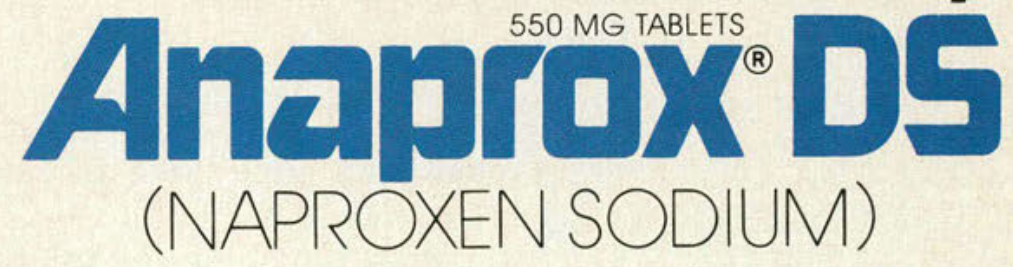

1. Ogilvie-Harris DJ, et al: Prostaglandin inhibition and the rate of recovery after arthroscopic meniscectomy. J Bone Joint Surg 1985;67-B:567-571.

2. Scoren RD, et al: Pain following periodontal surgery: Treatment with a nonnarcotic analgesic compared with two codeine combinations. Curr Ther Res $1987 ; 42: 463-471$

For brief summary of prescribing information, please see next page.

\section{S SYNTEX}


Gri toxicity. ANAPROX OR ANAPROX DS (NAPROXEN SODIUM) SINCE THEY CIRCULATE IN PLASMA AS THE NAPROXEN ANION. Acute interstitial nephritis with hematuria, proteinuria, and nephrotic syndrome has been reported Patients with impaired renal function, heart failure, liver dysfunction, patients taking duretics, and the renal function, heart tailure, liver dystunction, patients taking duretics, and the
elderly are at greater risk of overt renal decompensation. If this occurs, discon. elderly are at greater risk of overt renal decompensation. If this occurs, discon-
tinue the drug. Use with caution and monitor serum creatinine and/or creatinine tinue the drug. Use with caution and monitor serum creatinine and/or creatinine
clearance in patients with significantly impaired renal function. Use caution in clearance in patients with significantly impaired renal function. Use caution in
patients with baseline creatinine clearance less than $20 \mathrm{~m} /$ minute. Use the low. patients with baseline creatinine clearance less than $20 \mathrm{ml}$ minute, Use the low.
est effective dose in the elderly or in patients with chronic alcoholic liver disease or cirrhosis. Borderline elevations of liver tests may occur in up to $15 \%$ of or cirrhosis. Borderline elevations of liver tests may occur in up to $15 \%$ of
patients. Elevations of SGP Tor SGOT occurred in controlled trials in less than $1 \%$ patients. Elevations of SGPI or SGOI occurred in controlled trials in less than $1 \%$ of patients. Severe hepatic reactions, including jaundice and fatal hepatitis, have
been reported rarely. If liver disease develops or if systemic manifestations occur been reported rarely. If liver dssease develops or if systemic manifestations occur
(e.g. eosinophilia or rash), discontinue therapy. If steroid dosage is reduced or (e.g. eosinophilia or rash), discontinue therapy. If steroid dosage is reduced or
eliminated during therapy, do so slowly and observe patients closely for adverse eliminated during therapy, do so siowly and observe patients closely for adverse
effects, including adrenal insufficiency and exacerbation of arthritis symptoms. Determine hemoglobin values periodically for patients with initial values of 10 Determine hemoglobin values periodically for patients with initial values of 10
grams or less who receive long.term therapy. Peripheral edema has been grams or less who receive long.term therapy. Peripheral edema has been
reported for patients with restricted sodium intake, note that each tablet conreported for patients with restricted sodum intake, note that each tablet con-
tains approximately 25 or $50 \mathrm{mg}(1$ or $2 \mathrm{mEq})$ sodium. Use with caution in patients tains approximately 25 or $50 \mathrm{mg}(1$ or $2 \mathrm{mEg})$ sodum. Use with caution in patients
with fluid retention, hypertension or heart talure. The drug may reduce fever and with fluid retention, hypertension or heart falure. The drug may reduce fever and
inflammation, diminishing their diagnostic value. Conduct ophthalmic studies if any change or disturbance in vision occurs. Information for Patients: Side any change or disturbance in vision occurs. Information for Patients: Side
effects can cause discomfort and, rarely, more serious side effects, such as GI effects can cause discomfort and, rarely, more serious side effects, such as GI
bleeding. may result in hospitalization and even fatal outcomes. Physictans may bleeding, may result in hospitalization and even fatal outcomes. Physicans may
wish to discuss with patients potential risks and benefits of NSAIDs, particularly wish to dscuss with patients potential risks and benefits of NSAIDs, particularly
when they are used for less serious conditions where treatment without NSAIDS may be acceptable. Patients should use caution for activities requiring alertness may be acceptable. Patients should use caution for activities requiring alertness If they experience drowsiness, daziness, vertigo or depression during therapy. without warning symptoms, follow chronically treated patients and inform them of the importance of the follow-up. Orug Interactions: Use caution when giving of the importance of the follow.up. Orug Interactions: Use caution when giving concomitantly with coumarin-type anticaagulants; a hydantoin, sulfonamide or Drug Laboratory Test Interactions: May decrease platelet aggregation and Orug laboratory Test Interactions: May decrease platelet aggregation and
prolong bleeding time or increase urinary values for 17 -ketogenic steroids. Tempoprorily stop therapy for 72 hours before adrenal function tests. May interfere with urinary assays of 5HIAA. Carcinogenesis: A 2-year rat study showed no evidence of carcinogenicity. Pregnancy: Category B. Do not use during pregnancy dence of carcinogenicity. Pregnancy: Category B. Do not use during pregnancy use Pediatric Use: Single doses of $25-5 \mathrm{mg} / \mathrm{kg}$ (as naproxen suspension), with total daily dose not exceeding $15 \mathrm{mg} / \mathrm{kg} /$ day, are safe in children over 2 years of age.

Adverse Reactions: In a study. Gl reactions were more frequent and severe in theumatoid arthritis patients on $1650 \mathrm{mg} /$ day naproxen sodium than in those on $825 \mathrm{mg} / \mathrm{day}$. In children with juvenile arthritis, rash and prolonged bleeding times were more frequent. Gl and CNS reactions about the same, and other reactions less frequent than in adults. Incidence Greater Than 1\%, Probable Causal Relationship: Gl: The most frequent complaints related to the GI tract: constipe tion" heartburn," abdominal pain," nausea," dyspepsia, darrhea, stomatitis. CNS: headache* dizziness*" drowsiness", light-headedness, vertigo. Dermatologic: itching (pruritus)" skin eruptions," ecchymoses" sweating, purpura. Specia itching (prunitus), skin eruptions," ecchymoses," sweating, purpura. Special
Senses: tinnitus* hearing disturbances, visual disturbances. Cardiovascular: edema;" dyspnea," palpitations. General: thirst. "Incidence of reported reaction $3 \%-9 \%$. Where unmarked, incidence less than $3 \%$. Incidence Less Than $1 \%$. Probable Causal Relationship: Gl: abnormal liver function tests, colitis, GI bleed. ing and /or perforation, hematemesis, jaundice, melena, peptic ulceration with ing andier perforation, hematemesis, jaundice, melena, peptic ulceration with hyperkaiemia, interstitial nephritis, nephrotic syndrome, renal disease, renal failhyperkalemia, interstitial nephritis, nephrotic syndrome, renal disease, renal taircytopenia, leukopenia, thrombocytopenia. CNS: depression, dream abnormalities, inability to concentrate, insomiania, malaise, myalgia and muscle weakness. Dermatologic: alopecia, photosensitive dermatitis, skin rashes. Spe cial Senses: hearing impairment Cardiovascular: congestive heart tailure. Respratory: eosinophilic pneumonitis. General: anaphylactoid reactions, menstrua ratory: eosinophelic pneumonitis. General: anaphylactoid reactions, menstrual aplastic anemia, hemolytic anemia CNS: aseptic meningitis, cognitive dystunc aplastic anemia, hemolytic anemia. CNS: aseptic meningitis, cognitive dystunc tion. Dermatologic: epidermal necrolysis, erythema multitorme, photosensitivity Stevens-Johnson syndrome, urticaria. Gl: non-peptic GI ulceration, ulcerative stomatitis. Cardiovascular: vasculitis. General: angioneurotic edema, hyperstomatitis. Cardiovascilis:

glycemia, hypoglycemia

Overdosage: May have drowsiness, heartburn, indigestion, nausea, vomiting A few patients have had seizures. Empty stomach and use usual supportive meas. ures. In animals $0.5 \mathrm{~g} / \mathrm{kg}$ of activated charcoal reduced plasma levels of naproxen Dosage and Administration for Mild to Moderate Pain, Dysmenorrhea and lowed by $275 \mathrm{mg}$ every 6 to 8 hours. Total daily dose should not exceed $1375 \mathrm{mg}$ Dosage and Administration for Rheumatoid Arthritis, Osteoarthritis an Ankylosing Spondylitis: Recommended dose in adults is $275 \mathrm{mg}$ or $550 \mathrm{~m}$ twice daily. In patients who tolerate lower doses well, the dose may be increased to $1650 \mathrm{mg}$ per day for limited periods when a higher level of anti-inflammatory analgesic activity is required At this dosage, physicians should observe sufficient increased clinical benefits to offset potential increased risk. Caution: federal law prohibits dispensing without prescription. See package insert for full Prescribing Information.

Revised $9 / 90$ 133

\section{(continued)}

age who gave birth in 1990 rose $41 \%$ since 1975 .

According to the report, the increased number of adult Hispanics and Asians having babies is contributing substantially to this increased birth rate. Overall, higher-educated women tend to delay childbearing, according to the report.

\section{In the future, gene therapy} may be used to treat patients with emphysema and cystic fibrosis, based on results of animal experiments.

Scientists at the Pulmonary Division of the National Heart, Lung, and Blood Institute (NIH) transferred a recombinant human gene $\alpha$-1-antitrypsin to the respiratory epithelium of cotton rats via a genetically engineered adenoviral vector. Two days after the transfer, the $\alpha$-1-antitrypsin transcripts were seen in the rat lungs. The human $\alpha-1$-antitrypsin protein was seen in the rats' lungs for at least 1 week.

"The critical thing was being able to transfer a human gene to a specific organ like the lung and have the cells of that organ produce the protein that the gene codes for," explains researcher Ronald Crystal, MD.

"Our next step is to seriously consider gene therapy for $\alpha$-1-antitrypsin deficient pa- tients," says Dr Crystal. "But the big hurdle, and I don't want to minimize the difficulty, is safety," he cautions.

Complete study results appear in the April 19 issue of Science magazine.

\section{Conventional and uncon-} ventional cancer therapies fare no better in treating late-stage cancer, according to a study published in the April 25 issue of The New England Journal of Medicine.

Researchers at the University of Pennsylvania compared the length of survival and quality of life among cancer patients receiving treatment at two separate institutions. The LivingstonWheeler Medical Clinic in San Diego, Calif, treats patients with a vegetarian diet, coffee enemas, and an autogenous immune-enhancing vaccine. (Some patients at the Livingston-Wheeler Medical Clinic received chemotherapy after enrollment in this study.) Patients at the University of Pennsylvania Cancer Center received traditional chemotherapy.

A total of 78 patients participated in this study and were matched for age, sex, race, diagnosis, and the time between diagnosis and metastasis or disease recurrence. $\mathrm{Pa}$ tients were enrolled for $3^{1 / 2}$ 
years and were followed up approximately every 2 months until their death.

The median survival for patients in both groups was the same -15 months. Both groups of patients complained of appetite suppression, difficulty breathing, and pain, although the patients receiving traditional treatment reported slightly less discomfort.

Modest reductions in dietary fat intake aren't enough to reduce the risks of colon, breast, or prostate cancer, according to two separate studies.

Researchers at the Centers for Disease Control (CDC) found no significant difference in the risks for these cancers in persons who consumed an average of $32 \%$ of calories from fat compared with individuals whose fat intake amounted to $37 \%$ of their daily calories.

"A modest reduction will probably not appreciably reduce the [cancer] risk," said Tim Byers, MD, of the CDC at the annual convention of the Federation of American Societies for Experimental Biology in April in Atlanta.

"We will not see significant effects from the kinds of small dietary changes that are now under way in this country," he continued.

Dr Byers noted that a truly low-fat diet consists of five or six servings of fruits and vegetables and six servings of legumes or whole grains daily.

Similarly, researchers at the Harvard School of Public Health found men whose daily caloric intake consisted of an average of $24 \%$ fat had only $50 \%$ the rate of adenoma colon polyps as did men whose diet was made up of $41 \%$ fat.

"This would come close to explaining most of the variation we see between countries with colon cancer," said Harvard researcher Edward Giovannucci, MD. "This adds evidence to the fat and fiber hypothesis."

Although current government dietary recommendations say Americans should hold the line on fat consumption to $30 \%$ of their daily caloric intake, Daniel Nixon, MD, vice-president of the American Cancer Society, goes even further in his recommendations. "We've got to get people down to $25 \%$ to $20 \%$," he said.

\section{Most Americans favor} tough criminal laws for persons who knowingly infect others with the human immunodeficiency virus (HIV), according to a poll published in the May 6 issue of The National Law Journal.

Of the approximately 800 persons surveyed by tele- phone, $79 \%$ said that anyone who knowingly infects another person with the HIV should be charged with murder or assault. Ninety-three percent of the survey respondents believe that HIV-infected physicians and dentists should be legally required to inform their patients of their HIV infection.

Conducted by Penn \& Schoen Associates of New York, this survey was sponsored by The National Law Journal and LEXIS, a legal research service.

\section{ADJUNCT STAFF SURGEON}

The Department of Surgery of the Deborah Heart and Lung Center invites applications for the position of Adjunct Staff Surgeon for the Division of Cardiac Surgery.

This opportunity is appropriate for a Surgeon having completed his/her cardiac surgery training and desiring further operative experience in the setting of a busy and varied clinical practice.

Please send curriculum vitae to:

Lynn B. McGrath, MD Chairman, Dept. of Surgery

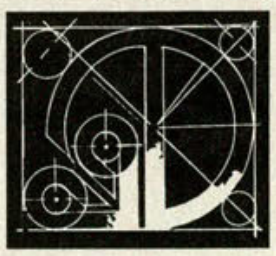

Deborah Heart and Lung Center 200 Trenton Road Browns Mills, NJ 08015 
COMING SOON FROM BRISTOL-MYERS SQUIBB 


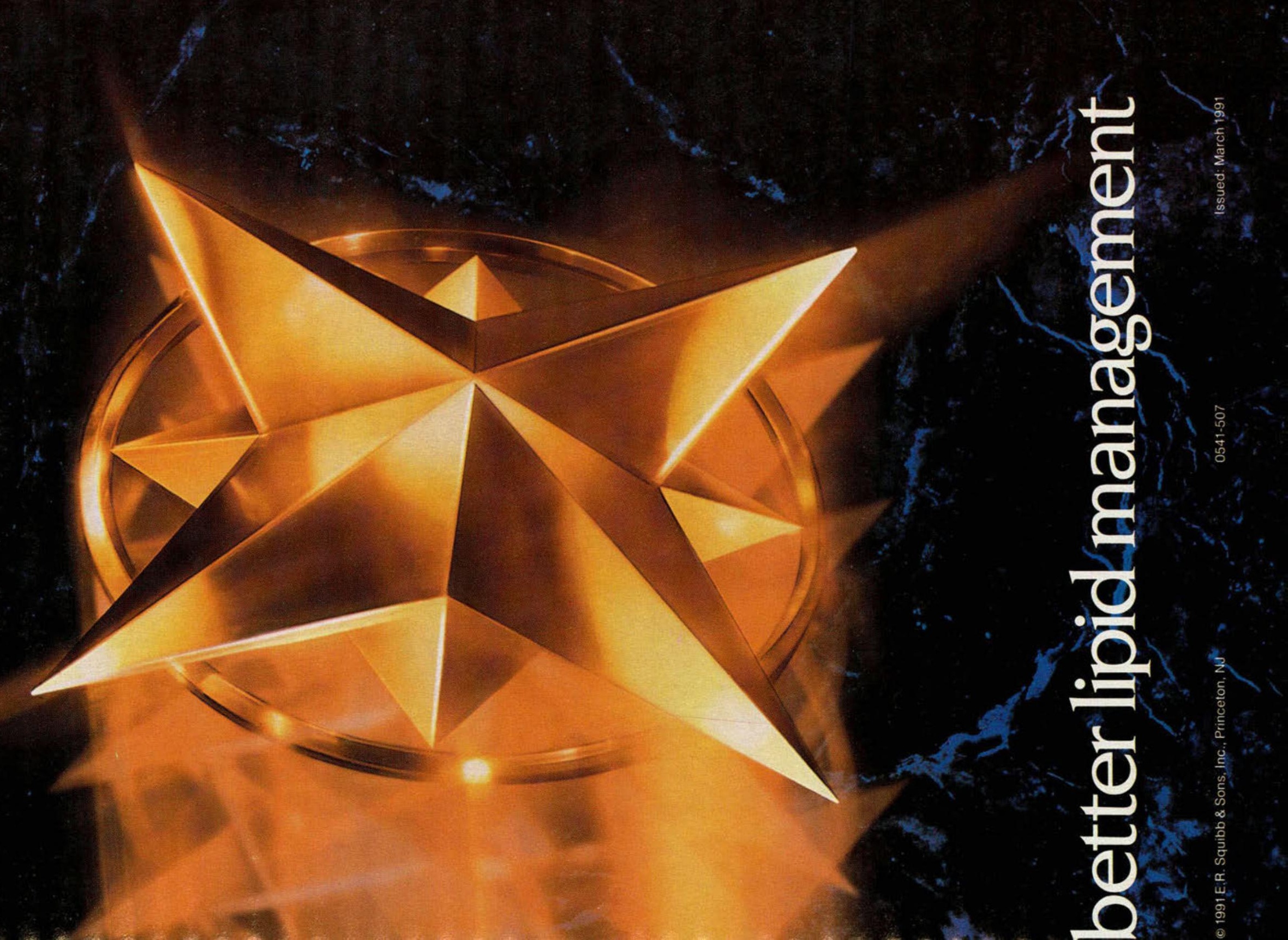

